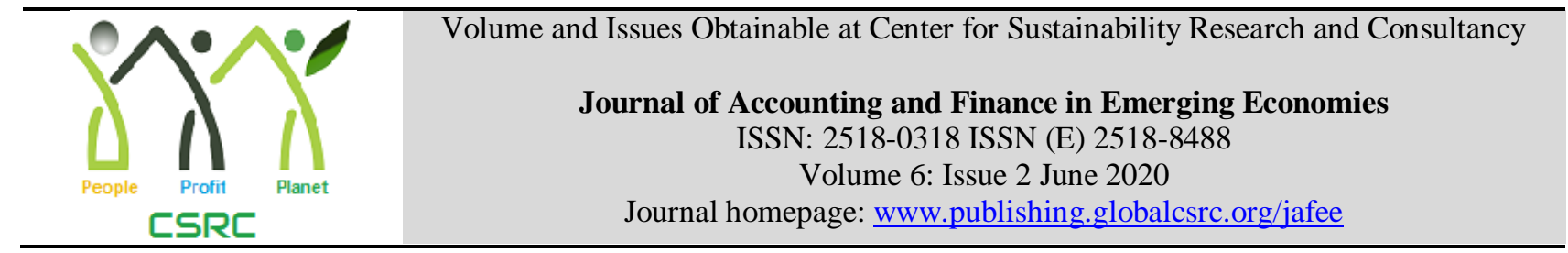

\title{
Framework Based Analysis of Corporate Leadership, Emotional Intelligence (EI) Competencies and Organizational Performance - A Developmental Perspective
}

\author{
${ }^{1}$ Muhammad Zia-ur-Rehman, ${ }^{2}$ Maria Zia \\ ${ }^{1}$ Associate Professor, National Defence University (Dept. of Leadership and Management Studies), \\ Islamabad Pakistan, drziaofficial@gmail.com \\ ${ }^{2}$ MPhil Scholar, BZU, Multan, mariaziaofficial@gmail.com
}

\begin{tabular}{l}
\hline ARTICLE DETAILS \\
\hline History \\
Revised format: May 2020 \\
Available Online: June 2020 \\
\\
Keywords \\
Leadership. EI competencies, \\
Organizational Performance, \\
Framework development \\
\hline
\end{tabular}

JEL Classification

M14, M19

\begin{abstract}
The study focuses on the issues of organizational performance, particularly related to developing corporate leadership to the level of effectiveness and the extended result as an outcome on organizational performance. We propose a model by plausibly linking the competencies related to emotional intelligence with effectiveness of corporate leadership, eventually fashioning out a high performance organization. In order to develop a framework, it includes conceptions grounded on EI as exogenous variable $(\xi)$, Effective corporate leadership (ECL) as endogenous $(\eta)$ variable and high performance organisation as outcome variable. The feedback composed was collected from 1171 corporate leaders serving in large business organizations across Pakistan. For analysis purpose, after data cleansing, SEM is employed to obtain results related to model fit and testing of hypotheses. Measurement and Structural Models approve the propositions of the study. After analysis, it is pertinent to mention that findings show great role of the competencies of EI with corporate leadership, and as a trickled down effect on overall organizational performance. The results also show how leadership can be developed to the level of effectiveness and thus can lead to achieve corporate reputation, employee commitment, market performance and financial performance of an organization. It is seen that the influence of EI competencies has not only the impact on the effectiveness of corporate leadership but also on overall organisational performance.
\end{abstract}

Corresponding author's email address: drziaofficial@gmail.com

Recommended citation: Rehman, M. Z., Zia, M. (2020). Framework Based Analysis of Corporate Leadership, Emotional Intelligence (EI) Competencies and Organizational Performance - A Developmental Perspective: Journal of Accounting and Finance in Emerging Economies, 6(2), 427-439

\section{Introduction}

Business Organizations undergo huge turmoil related to the performance, and they try to spend time, finance and efforts to diagnose the causes. Solutions like workplace environment till developing employees, managing bottom line, training sales persons and alike, have been practiced but results are not obtained as required. Therefore, researchers put emphasis on the need of developing leadership in 
organization but unfortunately still the leadership of organizations has been less studied from developmental perspective, thus the functional leadership remained ineffective. The sick or ineffective corporate leadership has remained a big problem for business organizations, especially producing low performance. The emphasis is put on this aspect and corporate leadership development related aspects also include the skills related to personal, interpersonal, managerial and societal effectiveness, thus including other softer skills development in corporate leadership improve even financial performance. In this scenario, it can be said that there are very few organisations called high performance as compare to low performance organisations.

\section{Literature Review}

Various perspectives of effective corporate leadership are taken into consideration, but here we focused on; personal, interpersonal, managerial and societal aspects, and each possess some critical characteristic features.

\subsection{Role of Emotional Intelligence in Developing Personal Effectiveness (PE)}

Emotional intelligence is increasingly getting significance, for developing corporate leaders in organisations all over the world. Various theories and models are followed and to some extent employed for incorporating the competencies related to emotional intelligence. The study used the model of EI developed by Denial Goleman (1998), which presents four main components of emotional intelligence, and these components considered supplying significant contribution for personal effectiveness (Sullivan, 2017). This builds up the sense that when people go on identifying their feelings and emotions, as they arise, then there is a need to manage the impulsive arousal of such energetic force, if not managed, such emotions can take over the charge of thinking and decision of people and this supports that people can become easy sufferer of their own strong emotions. Hence we propose that:

\section{Proposition 1: Emotional intelligence is positively related to the personal effectiveness dimension of effective corporate leadership.}

\subsection{Role of Emotional Intelligence in Developing Interpersonal Effectiveness}

Emotional intelligence is likely to have positive relationship with interpersonal effectiveness of corporate leadership. Interpersonal effectiveness of corporate leadership points towards those competencies which are considered crucial including trusting others, being compassionate, showing empathy towards others, being fair towards others, objectivity in decision making, encouraging others, guiding others and motivating others. Research shows that a person having higher level of the competency to manage own self could go for making choices which are better and information based, and it is due to that such decisions are not made under the control or pressure of emotions, instead they are made after management of emotions (Goleman et al, 2003). Social awareness refers to how people handle relationships and awareness of others' feelings, needs, and concerns. Additionally, personal behaviour is influenced through emotions (Van Deursen, 2015). Furthermore, relationship management deals with ability and proficiency to stir up sought-after reactions within other people. And the cluster of relationship management holds the abilities including; mentoring and coaching, inspirational leadership, influence, conflict management and teamwork. Hence we propose that:

\section{Proposition 2: Emotional intelligence is positively related to the interpersonal effectiveness dimension of effective corporate leadership}

\subsection{Role of Emotional Intelligence to Enhance Managerial Effectiveness}

The competencies related to self-awareness contain emotional self-awareness, which deals with recognizing own feelings and emotions, as well as the effects of them. Self-awareness can be likely to have positive relation with managerial effectiveness (Atan et al. 2019). Characteristics like team spirit, workplace productivity, and delegation of authority, empowerment and effective communication skills are considered for managerial effectiveness. Similarly corporate leaders should be candour with cohorts 
and need to try to exert efforts for workplace improvement. And effective leaders also emulate workplace values and build relationship by understanding customers' needs. Researchers are of the opinion that all the stakeholders are important in major decision making and to let the employees participate which is thought to be critical towards better performance and success (Mohamed et al., 2004; Marques, 2005; Chakraborty et al., 2004). Individuals having greater degree towards managing own self, are predicted to go for making better choices as such individuals are people with high self-management, who make more informed decisions because they are not likely for having controlled by the strong feelings and disruptive emotional stream, rather they manage the emotions and use appropriately (Goleman et al, 2003). This construct encompasses three valuable abilities including; being aware about organisation, understanding the levers of power and relations, and possessing empathy. Hence it is proposed that:

\section{Proposition 3: Emotional intelligence is positively related to the managerial effectiveness dimension of effective corporate leadership.}

\subsection{Role of Emotional Intelligence to Augment Societal Effectiveness (SE)}

Business organisations need to develop variety of strategies to cope with the interactions with societal issues and needs, and the natural environment around the corresponding business. On one side some organisations do not accept to have any responsibility towards societal issues while on the other hand, organisations acknowledge the significance of the relationship between business and the concerned societal aspects. Developing and learning organisations, try to contribute toward the issues of community (Zhang, 2017). Now-a-days, organisations try to become better partner in relation to society to involve the elements in society and thus benefit more. And this strategy works in favour of organisations, as such organisations also contribute towards a better world, and therefore translating the aspirations of the people into reality, which also needs education about self and society (Hallinger, 2019). Thus Emotional intelligence is considered significant for societal effectiveness as the components in relation to EI are possibly having positive effect on societal effectiveness. Thus, we propose as:

\section{Proposition 4: Emotional intelligence is positively related to the societal effectiveness dimension of effective corporate leadership.}

\subsection{Effective Corporate Leadership and Corporate Reputation}

Human Resource Development experts and researchers realized the significance of effective corporate leadership development, thus they tried to study the contribution of developing management and leadership, and their connections with the performance of organization (Baldwin \& Padgett, 1993; Holton \& Lynham, 2000; Kuchinke, 2000). Sosik and Megerian's (1999) research related to the linkages of behaviour and emotional intelligence employed a wider description about EI as compare to using a narrow framework and viewpoint as defined by Salovey and Mayer (1997). The discipline of Human Resource Development helps understanding to improve the performance; of individual persons as well as groups in organisations, as researchers favour that HRD interventions can be employed in relation to performance (Swanson, 1995). Therefore, corporate leadership can be taken under consideration as it is considered crucial in order to build and develop corporate reputation as an outcome of organisations (Ferguson, Deephouse \& Ferguson, 2003). Hence we propose that:

\section{Proposition5: Effective corporate leadership is positively related to better corporate reputation.}

\subsection{Employee Commitment and Effective Corporate Leadership}

Among other organisational performance related measures, employees play vital role as if they stay committed with the organisation and remain contributing their best, organisation grow and perform high. But if there is no effective corporate leadership, organisational performance cannot be high as they have great influence on organisational performance's every aspect. Therefore, organisational commitment is determined by organisational factors including leadership (Luthans, 1998). Human Resource Development provides a strategic contribution, through furnishing assurance about the appropriate match 
of the people' competencies with the requirements of the current performance of organisations (Torraco \& Swanson, 1995). Corporate leadership is significant for employee commitment and effective leadership may have positive and significant relationship with future outcomes because it is related to high motivation of the employees. Therefore, this can be depicted through increased trustworthiness and towards achievement of increased employee commitment. Thus we can propose as:

\section{Proposition 6: Effective corporate leadership is positively related to high employee commitment of an organisation.}

\subsection{Effective Corporate Leadership and Market Performance}

Another measure related to organisational performance is market performance and market performance encompasses various elements including market orientation, which can lead an organisation to high market performance. In getting competitive advantage, it is necessary to develop the organisational staff especially the corporate leadership to have effective planning strategies (Wilson, 2001) as to achieve competitive advantage in the market performance; it needs strategic planning from the corporate leadership side to have the market performance towards increasing trend. The leadership of organisations needs to have competencies and attributes to achieve such position. As there is a need of leadership in various stages, for becoming a competing, successful and high performing organisation, it needs to have leaders developed at all levels (Greenspan, 1989). Hence we propose that:

\section{Proposition 7: Effective corporate leadership is positively related to increased market performance of an organisation.}

\subsection{Financial Performance and Effective Corporate Leadership}

Many international business oriented organisations have been and are trying to acknowledge the significance of corporate leadership for organisations. In order to do so, there is a dire necessity for developing effective corporate leadership, thus the emerging concept is banking on leadership development (Froman, 2019). In order to have better or high financial returns, there is a need of corporate leadership development, equipped with the competencies related to the understanding of the people dealing with financial matters. Therefore, financial leadership as a concept is emerging where there is a need of awarded leadership related to personal, interpersonal, managerial and societal effectiveness of them. Those organisations, which have better workplace at mosphere with greater culture of learning, show higher organisational effectiveness (Tannenbaum, 2005). Therefore we propose that:

\section{Proposition 8: Effective corporate leadership is positively related to better financial performance of an organisation.}

\section{Methodology}

Twelve criteria were used as values for the indicator variables; the latent variables and PLS SEM using Smart PLS, (Ringe et al., 2005) was fitted to these data. The hypotheses $\left(\mathrm{H}_{1}-\mathrm{H}_{8}\right)$ were represented in PLS SEM as paths in the hypothesised model; the weightings for the first order reflective latent variables 'EI', 'ECL' and 'HPO', onto the second order latent variables ('EI', 'PE', IE', 'ME', 'SE', 'CR', 'EC', 'MP' and 'FP') are also present as paths that represent $\mathrm{H}_{1}, \mathrm{H}_{2}, \mathrm{H}_{3}, \mathrm{H}_{4}, \mathrm{H}_{5}, \mathrm{H} 6, \mathrm{H}_{7}$, and $\mathrm{H}_{8}$ respectively. To test relationships, among structural path joining these exogenous latent variables, are also present in the model. The measurement model for the SEM was then tested to further confirm the presence of the corresponding first order reflective latent variables as well as the second order latent variable and that the putative indicator variables, all fitted onto their designated constructs. The structural path model was tested for significance, leading to confirmation, or otherwise, of the corresponding hypotheses.

\subsection{Instrumentation}

Our research model draws from the research works of Goleman, Tim Lowder and Delaney \& Huselid 1996, Harel, Tzafrir 1999, Khuleep Singh 2004. Instruments employed for collection of data are 
discussed.

\subsection{The Competencies of Emotional Intelligence}

After having gone through the process of refinement, the Emotional Social Competency Inventory (ESCI) was left with lesser number of competencies as 12 instead of 18, ultimately. Thus emotional social competency inventory is a new authentic tool for the assessment of emotional intelligence and the authors of this measure defined intelligence by conceptualising it as an ability and acknowledging that this ability can be measured directly by those people who answer the questions, and then through the process of evaluation and the assessment regarding the correctness of the answers provided (Mayer, 2002). This measure is based on the refinement of ECI and was refined by the researchers to make a more authentic and appropriate tool to measure EI. It was also to enhance its reliability and validity for research purpose (Boyatzis, 2000; 2002).

\subsection{Effective Corporate Leadership}

Effective Corporate Leadership is measured through the sub scales based on the intensive study done by Tim Lowder (2007), Palanski and Yammarino (2007), House R.J. et al (2004), and Mendenhall (2001). Mostly, the section is based on the study presented by Tim Lowder in 2007, a professor of Capella University, USA. This instrument measured the variables of effective corporate leadership on the basis of various sub-scales under four important clusters: (a) Personal effectiveness, (b) Interpersonal effectiveness, (c) Managerial effectiveness and (c) Societal effectiveness of corporate leadership. A seven point scale was used, starting from strongly disagree $=1$ to strongly agree $=7$ with a central point 'neutral'.

\subsection{Organisational Performance}

Organisational performance is assessed through observing the indicators of performance objectively; productivity per employee, return on sales and profit per employee, and such assessment of the objective performance of organisation is proposed by Huselid (1995). This construct included various sub-scales under the four major aspects; (a) corporate reputation, (b) Employee commitment, (c) Performance related to market and (d) Organisation performance related to finance. A seven point scale was used, starting from poor $=1$ to good = 7 with 'adequate'. And the last part of the instrument deals with the demographic variables including eight elements like; gender, experience, education, age, life of organisation, number of employees, and sector of business.

\subsection{Sampling Technique and Procedures}

.To target the maximum population of corporate leadership of public organisaitons, the questionnaire was sent to a large number of potential respondents. Convenience sampling was employed while the sampling frame was the Islamabad stock exchange and the questionnaires were administered to the Corporate Level (C-Level) executives of the public organisaitons enlisted on Islamabad Stock Exchange (ISE). A total of 750 questionnaires were sent, while 331 questionnaires were returned from 76 public organisations, making a response rate of $44 \%$. Some were not qualifying, therefore a 17 of such were filled feedbacks were discarded before analysis.

\subsection{Exogenous Variables}

Emotional intelligence was considered as exogenous variable with its constructs as self-awareness, selfmanagement, social awareness and relationship management.

\subsection{Endogenous Variables}

Effective corporate leadership is taken as endogenous variable with its constructs including societal effectiveness, managerial effectiveness, interpersonal effectiveness, and personal effectiveness. 


\subsection{Outcome Variables}

High performance of organisations was outcome endogenous variable with its constructs including corporate reputation, employee commitment, market performance and financial performance.

\section{Analysis and Findings}

Structural Equation Modelling (SEM) was employed to test the association of the variables in the model presented. It is used to test the hypothesized relationship among our study variables. Two steps were used to analyze the relationship; association of the competencies of EI with corporate leadership qualities, and then the effect of corporate leadership on the organizational performance.

\subsection{SEM Overall Model}

The SEM model contains two inter-related models: the measurement model (the manifest variables related to EI, ECL and HPO) and the structural model (the relationship among the twelve latent variables). Both models were explicitly defined in the study. In measurement model, the constructs of the model were explained, and each construct got assigned and relevant observed variables. SEM was estimated to provide an empirical measure of the relationships among manifest variables and the constructs. The results of the model fit, allowed the researcher to match theory against reality as represented by sample data in order to observe how well the theory fits the data. The fit of the proposed measurement model was tested through data analysis, model hypotheses were also tested and path diagram was developed, which is the graphical representation that employs arrows and parameters to depict various relationships that show relationship among a range of variables under evaluation. Within the context of SEM, exogenous $(\xi)$ and endogenous $(\eta)$ constructs were explained. The hypothesized model consisted of four exogenous constructs and eight endogenous constructs. The exogenous constructs included self-awareness, self-management, social awareness and relationship management having combined effect as 'emotional intelligence'. They are determined by the elements, which are outside the model hypothesized, and not influenced by any other latent variable $(\mathrm{LV})$ in the model. Therefore no hypotheses truly predict any of these constructs in the study. The endogenous constructs include variables related to ECL and HPO, and endogenous construct in the model contribute toward one major construct 'effective corporate leadership' and to other endogenous constructs, so outcomes lie under hypotheses and a predictor for others.

\subsection{Measurement Model}

The study looked at validating the reliability of individual items, and relationships between individual constructs, which are significant for the study. It was established that where relationships between individual items and constructs were less than 0.5 in value, relationships were considered weak and those items could be discarded and where the relationships between the main construct and sub-constructs were less than 0.7 in value, relationships were considered weak and those sub-constructs could be discarded (Hair et al., 2007). The measurement model of the latent variables is used to test the construct validity. Three unobserved variables were in the model, with their sub-scales and the indicators. Each sub-scale was measured through observed indicators. The exogenous variables and endogenous variables were mentioned as EI, ECL and HPO. Forty-eight observed variables (indicators) that represent the four exogenous latent constructs (SA, SM, SA, RM) are related to EI. They were measured weights and exceeded 0.50, while thirty four observed variables (indicators) were related to four latent constructs (PE, IE, ME and SE) related to ECL, and lastly 14 observed variables (indicators) were related to four latent constructs (CR, EC, MP and FP) related to HPO. It showed the degree to which the set of measures indicate the common latent construct. Construct reliability is based on estimates of model parameters, and the mostly used measure for internal consistency reliability is Cronbach's $\alpha$. The coefficient value of 0.7 or greater, indicate good reliability (Hair et al. 2010). So this indicates that the items are correlated adequately, with each making a contribution towards a measure of their designated construct. The study shows high construct reliability as all the values are above 0.7 .

Table 1: Descriptive statistics 


\begin{tabular}{lcccccccc}
\hline & $\begin{array}{c}\text { Experienc } \\
\mathrm{e}\end{array}$ & $\begin{array}{c}\text { Educatio } \\
\mathrm{n}\end{array}$ & Age & $\begin{array}{c}\text { Gende } \\
\mathrm{r}\end{array}$ & $\begin{array}{c}\text { Job/Positio } \\
\mathrm{n}\end{array}$ & $\begin{array}{c}\text { Life of } \\
\text { Org. }\end{array}$ & $\begin{array}{c}\text { No. of } \\
\text { Emp. }\end{array}$ & $\begin{array}{c}\text { Business/ } \\
\text { Organisati } \\
\text { on }\end{array}$ \\
\hline $\mathrm{N} \quad$ Valid & 314 & 295 & 309 & 298 & 310 & 313 & 314 & 314 \\
\cline { 2 - 8 } Missing & 0 & 19 & 5 & 16 & 4 & 1 & 0 & 0 \\
Mean & 1.95 & 1.87 & 3.38 & 1.14 & 3.01 & 2.00 & 2.00 & 2 \\
Mode & 2 & 2 & 4 & 1 & 3 & 2 & .000 & .000 \\
Std. & .214 & .665 & .762 & .345 & .948 & & \\
Deviation & & & & & & & \\
\hline
\end{tabular}

After conducting descriptive analysis, the data were analysed to test the hypotheses, but before analysis, the validity and reliability were assessed through different tests.

Table 2: Assessment of the Measurement Model

\begin{tabular}{|c|c|c|c|c|}
\hline $\begin{array}{c}\text { Variable } \\
\text { constructs }^{\dagger}\end{array}$ & $A V E^{d}$ & $\rho_{\mathrm{c}}^{\mathrm{b}}$ & $\mathrm{R}^{2}$ & $\alpha^{\mathrm{c}}$ \\
\hline CR (3) & 0.9401 & 0.9792 & 0.6671 & 0.968 \\
\hline EC (3) & 0.9417 & 0.9798 & 0.6845 & 0.969 \\
\hline $\mathrm{FP}(4)$ & 0.9369 & 0.9834 & 0.7164 & 0.977 \\
\hline IE (8) & 0.8564 & 0.9795 & 0.3936 & 0.975 \\
\hline ME (13) & 0.8731 & 0.9889 & 0.4982 & 0.987 \\
\hline MP (4) & 0.9205 & 0.9789 & 0.4164 & 0.971 \\
\hline PE (9) & 0.8081 & 0.9743 & 0.4878 & 0.970 \\
\hline RM (17) & 0.7084 & 0.9762 & NA & 0.973 \\
\hline SA (6) & 0.7388 & 0.9443 & NA & 0.929 \\
\hline SE (4) & 0.8336 & 0.9524 & 0.3554 & 0.933 \\
\hline SM (15) & 0.6972 & 0.9717 & NA & 0.968 \\
\hline SOA (10) & 0.6803 & 0.955 & NA & 0.947 \\
\hline
\end{tabular}

$\dagger$ The number in parentheses indicates the items in the scale

b Composite reliability (Fornell \& Larcker, 1981)

c Cronbach's Alpha (Cronbach, 1951)

$d$ Average variance extracted

The measurement model was tested and the results of reliability after assessing the measurement model are presented. The values in the table indicate the robustness of the measures on the basis of the reliabilities of internal consistency as shown through CR. And the composite reliabilities about the various measures of the study model range from 0.86 to 0.95 . Furthermore, as having consistency with the guiding principle laid down by Fornell \& Larcker (1981), the average variance extracted (AVE) for each measure of the study, well exceeded the limit of 0.50 (the minimum AVE was 0.68).

\subsection{Assessment of the Measurement Model}

Measurement model is a sub-model in structural equation modelling that; (1) specifies the indicators for each construct, and (2) assesses the reliability of each construct for estimating the causal relationships. 
For assessing the measurement model, discriminant as well as convergent validity was examined; the convergent validity was tested through assessing the value of Cronbach's $\alpha$, composite reliabilities (CR), Average Variance Extracted (AVE), and item loadings, where all exceeded the recommended threshold values; 0.70 for composite reliabilities (Fornell \& Larcker, 1981), 0.70 for Cronbach's $\alpha, 50 \%$ for Average Variance Extracted (AVE), and 0.707 for items loadings (Hair, Black, Babin, Anderson, \& Tatham, 2006).

Table 3: Discriminant Validity (Inter-correlations) of Variable Constructs

\begin{tabular}{|c|c|c|c|c|c|c|c|c|c|c|c|c|}
\hline & $\mathrm{CR}$ & $\mathrm{EC}$ & FP & IE & ME & MP & $\mathrm{PE}$ & $\mathrm{RM}$ & SA & SE & SM & SOA \\
\hline $\mathrm{CR}$ & $0.969588^{a}$ & & & & & & & & & & & \\
\hline $\mathrm{EC}$ & 0.779 & 0.970412 & & & & & & & & & & \\
\hline FP & 0.8344 & 0.7981 & 0.967936 & & & & & & & & & \\
\hline IE & 0.6193 & 0.6346 & 0.6312 & 0.925419 & & & & & & & & \\
\hline ME & 0.729 & 0.7447 & 0.7596 & 0.5291 & 0.934398 & & & & & & & \\
\hline MP & 0.5759 & 0.6305 & 0.6117 & 0.4883 & 0.5995 & 0.959427 & & & & & & \\
\hline PE & 0.6621 & 0.6805 & 0.6841 & 0.4701 & 0.6548 & 0.4861 & 0.898944 & & & & & \\
\hline $\mathrm{RM}$ & 0.4728 & 0.538 & 0.5203 & 0.417 & 0.5081 & 0.388 & 0.478 & 0.841665 & & & & \\
\hline SA & 0.4064 & 0.3583 & 0.3997 & 0.3426 & 0.3237 & 0.2892 & 0.3766 & 0.1831 & 0.859535 & & & \\
\hline $\mathrm{SE}$ & 0.5937 & 0.5297 & 0.6246 & 0.4323 & 0.4696 & 0.4609 & 0.4841 & 0.4426 & 0.2375 & 0.913017 & & \\
\hline SM & 0.6433 & 0.6801 & 0.6766 & 0.5462 & 0.5804 & 0.5584 & 0.5682 & 0.2897 & 0.3968 & 0.5293 & 0.834985 & \\
\hline SOA & 0.4908 & 0.5139 & 0.4717 & 0.3927 & 0.4645 & 0.3683 & 0.4961 & 0.2908 & 0.07 & 0.3044 & 0.4753 & 0.824803 \\
\hline
\end{tabular}

A square root of AVE

Bootstrap t-statistics for $\mathrm{B}=1000$ bootstrap resamples. ${ }^{*} \mathrm{P}<0.005$.

The above table reports the results of testing the discriminant validity of the measurement scales. The bold elements in the matrix diagonals, representing the square roots of the AVEs, are greater in all cases than the off-diagonal elements in their corresponding row and column, supporting the discriminant validity of the scales of the study. The inter-construct correlation matrix is illustrated in Table with square root of Average Variance Extracted (AVE).

\subsection{Cross Loadings}

Assessing through PLS was then carried out by verifying that the AVE of each construct was larger than its correlations with the other constructs, and that each item loading on to the respective construct was much higher than on the other constructs.

Table 4: Factor Loadings (Bold) and Cross Loadings

\begin{tabular}{|c|c|c|c|c|c|c|c|c|c|c|c|c|}
\hline & $\mathrm{CR}$ & $\mathrm{EC}$ & FP & $\mathrm{IE}$ & ME & MP & $\mathrm{PE}$ & $\mathrm{RM}$ & SA & SE & SM & SoA \\
\hline CR1 & 0.9595 & 0.7437 & 0.8188 & 0.6065 & 0.6993 & 0.5567 & 0.6283 & 0.4632 & 0.4137 & 0.573 & 0.6259 & 0.4674 \\
\hline $\mathrm{CR} 2$ & 0.9931 & 0.7702 & 0.8281 & 0.6177 & 0.7202 & 0.5732 & 0.6599 & 0.4617 & 0.4126 & 0.5844 & 0.6362 & 0.4837 \\
\hline CR3 & 0.9557 & 0.7521 & 0.7797 & 0.5766 & 0.7009 & 0.545 & 0.6371 & 0.4503 & 0.355 & 0.5695 & 0.6089 & 0.4764 \\
\hline $\mathrm{EC} 1$ & 0.7557 & 0.9643 & 0.766 & 0.6062 & 0.7231 & 0.6072 & 0.6639 & 0.5191 & 0.3454 & 0.5138 & 0.6349 & 0.4836 \\
\hline
\end{tabular}




\begin{tabular}{lllllllllllll} 
EC2 & 0.7618 & $\mathbf{0 . 9 8 6 5}$ & 0.7821 & 0.6182 & 0.7291 & 0.6141 & 0.6644 & 0.5277 & 0.3507 & 0.5239 & 0.6643 & 0.5037 \\
EC3 & 0.7504 & $\mathbf{0 . 9 6 0 2}$ & 0.7754 & 0.6232 & 0.7158 & 0.6142 & 0.6528 & 0.5193 & 0.3471 & 0.5043 & 0.6807 & 0.5089 \\
\hline
\end{tabular}

The above Table shows the cross loadings of the indicators related to each construct. The cross loadings were drawn to assess the respective loading of the measurement items onto their respective construct, thus analysing convergent validity of each construct.

Structural model is a set of one or more dependence based relationships, linking the model constructs. The structural model is most useful in representing the interrelationships of variables among the dependence relationships. In the study, the structural model showed the path diagram of the variables under study, the diagram is presented. A conceptual model runs through the very beginning from the diagram till the outcomes, therefore, through the statistical analysis it was found that there was high correlation among the variables and effective corporate leadership development, and as a construct it was emerged. For the structural model the relationships between individual constructs were explored. For analyses of the relationships, SmartPLS 2.0 (Ringle et al., 2005) was used, and tests for the path coefficients were based on t-values calculated, using the bootstrap facility. A total of 1000 iterations were used to produce a converged and stable fit.

Figures showing the relationships are depicted in tabular form.



Figure 1 Measurement and structural model depicting latent and manifest variables

In the structural model / inner model, the exogenous latent constructs $(\xi)$ shows the significant contribution towards the endogenous latent constructs $(\eta)$. It can also be noticed that except few, the paths $(\gamma)$ connecting $(\xi)$ to $(\eta)$, statistically represent significant values. The paths connecting one $(\eta)$ to another are designated with $(\beta)$ and they were found having reliable values. 


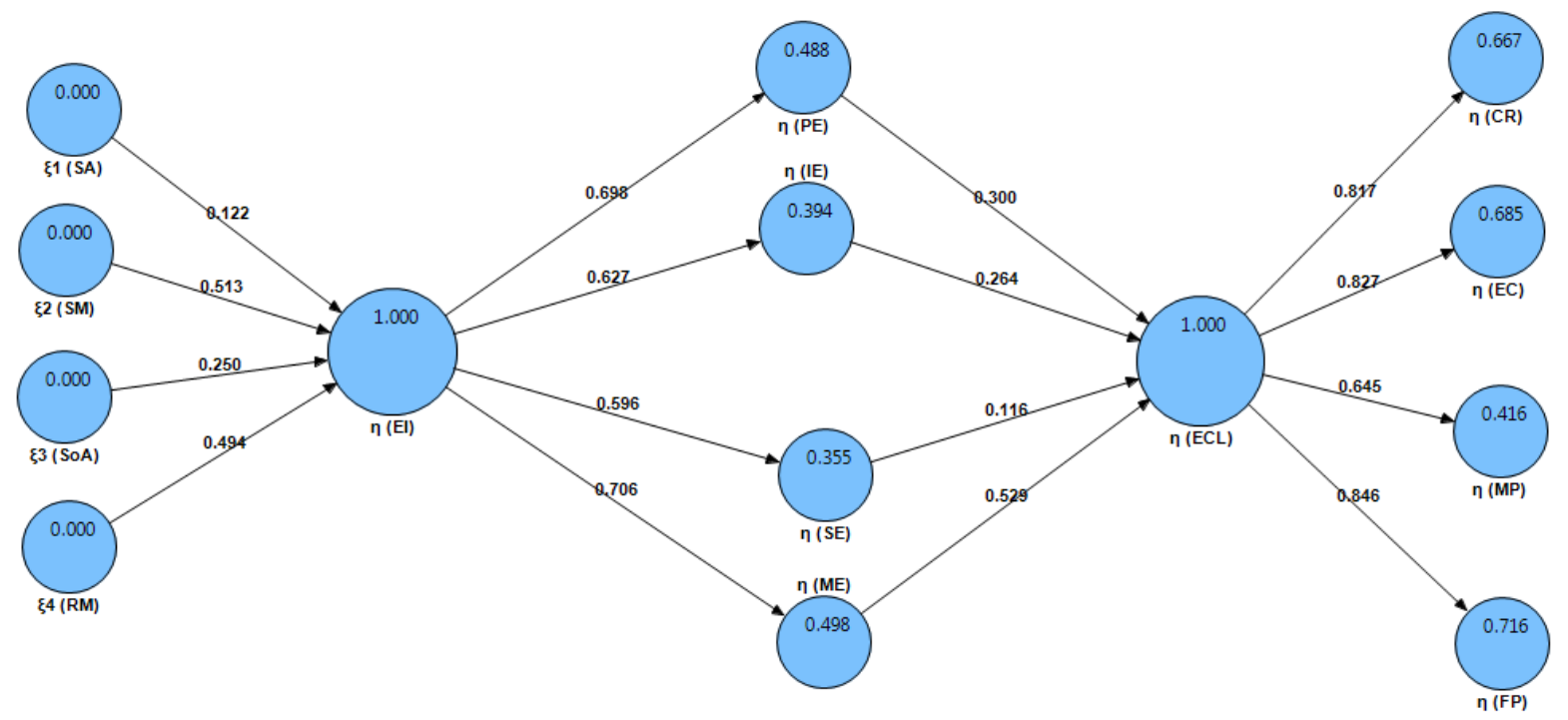

Figure 2. Inner model showing latent variables

The structural model shows that for additional one standard deviation ceteris paribus change; one would expect an increase in the predicted variables. The standardized path-coefficients were shown which indicate that if $\mathrm{EI}$ increases by 1 standard deviation, there could be an expected 0.698 increase in standard deviation in $\mathrm{PE}$, and this is a direct effect. And if $\mathrm{EI}$ is augmented by 1 standard deviation, IE is considered to be enhanced by 0.627 , ME by 0.706 , and SE by 0.596 standard deviation, respectively. Similarly, related to organisational performance, if effective corporate leadership increases by 1 standard deviation, there would supposed to be an increase in CR by 0.817 , in EC by 0.827 , in MP by 0.645 and in FP by 0.846 . In order to see the path coefficients, the calculation / PLS algorithm was run again, to calculate values of the structural paths of inner model.

Table 5: T-statistics with bootstrap analysis depicting the paths

\begin{tabular}{lcccc}
\hline & Sample Mean & $\begin{array}{c}\text { Standard } \\
\text { Deviation }\end{array}$ & Standard Error & T-Statistics \\
\hline$\eta($ ECL) $->\eta(\mathrm{CR})$ & 0.81 & 0.04 & 0.0426 & 19.19 \\
$\eta(\mathrm{ECL})->\eta(\mathrm{EC})$ & 0.83 & 0.03 & 0.038 & 21.79 \\
$\eta(\mathrm{ECL})->\eta(\mathrm{FP})$ & 0.85 & 0.03 & 0.0349 & 24.26 \\
$\eta(\mathrm{ECL})->\eta(\mathrm{MP})$ & 0.64 & 0.07 & 0.0761 & 8.47 \\
$\eta(\mathrm{EI})->\eta(\mathrm{IE})$ & 0.63 & 0.06 & 0.0657 & 9.54 \\
$\eta(\mathrm{EI})->\eta(\mathrm{ME})$ & 0.71 & 0.05 & 0.0538 & 13.12 \\
$\eta(\mathrm{EI})->\eta(\mathrm{PE})$ & 0.69 & 0.05 & 0.0571 & 12.23 \\
$\eta(\mathrm{EI})->\eta(\mathrm{SE})$ & 0.60 & 0.06 & 0.0619 & 9.63 \\
$\eta(\mathrm{IE})->\eta(\mathrm{ECL})$ & 0.26 & 0.02 & 0.0254 & 10.39 \\
$\eta(\mathrm{ME})->\eta(\mathrm{ECL})$ & 0.53 & 0.03 & 0.0319 & 16.57 \\
$\eta(\mathrm{PE})->\eta(\mathrm{ECL})$ & 0.29 & 0.02 & 0.0232 & 12.89 \\
$\eta(\mathrm{SE})->\eta(\mathrm{ECL})$ & 0.48 & 0.07 & 0.0717 & 6.88 \\
$\xi_{1}(\mathrm{SA})->\eta(\mathrm{EI})$ & 0.11 & 0.03 & 0.0392 & 3.10 \\
$\xi_{2}(\mathrm{SM})->\eta(\mathrm{EI})$ & 0.11 & 0.01 & 0.0158 & 7.36 \\
$\xi_{3}(\mathrm{SoA})->\eta(\mathrm{EI})$ & 0.50 & 0.06 & 0.0618 & 8.30 \\
$\xi_{4}(\mathrm{RM})->\eta(\mathrm{EI})$ & 0.24 & 0.04 & 0.0441 & 5.68 \\
\hline
\end{tabular}

Note: T-values are calculated through bootstrapping routine with 200 cases and 1000 samples

T-statistics show significance for each variable in the Table above. On the basis of t-statistics, $p$-values of the predictor variables for latent endogenous variable; SA, SM, SoA, RM, and the predictor second order variables $\mathrm{PE}, \mathrm{IE}, \mathrm{ME}, \mathrm{SE}$ for endogenous latent variable ECL, were computed, showing the variables significantly contributing towards their respective construct. 
Table 6: Values showing the significance of each path in analysis

\begin{tabular}{lcc}
\hline Paths & T-Statistics & P-values \\
\hline ECL -> CR & 19.19 & 0.00 \\
ECL -> EC & 21.79 & 0.00 \\
ECL -> FP & 24.26 & 0.00 \\
ECL -> MP & 8.47 & 0.00 \\
EI -> IE & 9.54 & 0.00 \\
EI -> ME & 13.12 & 0.00 \\
EI -> PE & 12.23 & 0.00 \\
EI -> SE & 9.63 & 0.00 \\
IE -> ECL & 10.39 & 0.00 \\
ME -> ECL & 16.57 & 0.00 \\
PE -> ECL & 12.89 & 0.00 \\
RM -> EI & 6.88 & 0.00 \\
SA -> EI & 3.10 & 0.00 \\
SE -> ECL & 7.36 & 0.00 \\
SM -> EI & 8.30 & 0.00 \\
SOA -> EI & 5.68 & \\
\hline
\end{tabular}

Above table shows that relationships were reliable and the t-value for all paths were well above 1.645, indicating highly significant relationships.

\section{Conclusion and Recommendations}

From human resource development perspective, internal elements are studied intensively and especially the corporate leadership of organisations is regarded as the most important asset of an organisation. The study was conducted on the basis of exploring the problems related to organisational performance and to study how to achieve high performance organisation in now-a-days' competitive business world. In order to get high performance, corporate leadership was found as vital but it was considered difficult to let them understand that they need development to get better performance of their organisations, because psychologically they have the concept that they are already developed ones and need no further development and improvement. Thus development efforts are exerted more and more towards the lower level employees like sales force and other workers in organisations, ignoring the crucial need to develop corporate leadership. But the research went through a number of other researches done and found that the most of the impact on an organisation's performance is due to the top level corporate leadership of the originations, which can push organisations towards the worse or better situation. So the researchers presented and proposed theories and models towards the development of organisational top-level leadership, to get better or even high performance organisations. It was also found that effective corporate leadership, as measured through four aspects, was positively related to the high performance originations.

Therefore, conclusively, those corporate leaders, who are high in the competencies related to personal, 
interpersonal, managerial and societal effectiveness, can help the companies achieve the status of high performance organisations, by enhancing different aspects like corporate reputation, employee commitment, market performance and financial performance. Hence, emotional competencies, if the corporate leaders are aware of, are found to have effectiveness in the sense of personal, interpersonal, managerial and societal levels. This ultimately leads to the high performance organisations and thus to achieve sound economy in the current turbulent times of fluctuations. Future studies may focus more on comparing the public and private organisational leadership, in order to have better conceptualization of the framework.

\section{References}

Salovey, P., Mayer, J., Goldman, S., Turvey, C., \& Palfai, T. (1995). Emotional attention, clarity, and repair: exploring emotional intelligence using the Trait Meta-Mood Scale. In J. W. Pennebaker (Ed.), Emotion, Disclosure, and Health (pp. 125-154). Washington, DC: American Psychological Association

The Essentials of High Performance Organizations by Mark Vickers, Institute for Corporate Productivity, 2007

Daniel Goleman (1998), Working With Emotional Intelligence. New York: Bantam.

Dulewicz, V., \& Higgs, M. (2003). Leadership at the top: The need for emotional intelligence in organizations. International Journal of Organizational Analysis , 11 (3), 193-210.

Rozell, E. J., Pettijohn, C. E., and Parker, R. S. (2001). An empirical evaluation of emotional intelligence: The impact on management development. Journal of Management Development, 21(4), 272-289.

Rozell, E. J., Pettijohn, C. E., and Parker, R. S. (2001). An empirical evaluation of emotional intelligence: The impact on management development. Journal of Management Development, 21(4), 272-289.

Nyhan, Ronald C., and Herbert A. Marlowe. (1997). The psychometric properties of the organizational trust inventory. Evaluation Review 614-635.

Mohamed, A. A., Wisnieski, J., Askar, M., \& Syed, I. (2004). Towards a theory of spirituality in the workplace. Competitiveness Review, 14(1/2), 102-107.

House, R. J. and Shamir, B. (1993). Toward an integration of transformational, charismatic and visionary theories of leadership. In M. Chemers and R.

Hogan, R., Curphy, G. J. and Hogan, J. (1994). What we know about leadership. American Psychologist, 49, 493-504.

Thorndike, R. L., \& Stein, S. (1937). An evaluation of the attempts to measure social intelligence. Psychological Bulletin, 34, 275-284

Pool, P. and Cotton, C. W. (2004). Emotional Intelligence: Improving the Odds of Leader Success, 1-8.

Baker, D. E., Walsh, M. B., \& Marjerison, L. (2000). Developing high performance leadership at the process level. In E. F. Holton \& S. S. Naquin (Eds.), Developing high-performance leadership competency (Vol. 6, pp. 47-72). Baton Rouge, LA: Academy of Human Resource Development.

Sosik, J. J., and Megerian, L. E. (1999). Understanding leader emotional intelligence and performance: the role of self-other agreement on transformational leadership perceptions. Group and Organization Management, Vol. 24, pp. 367-390.

Sosik, J. J., and Megerian, L. E. (1999). Understanding leader emotional intelligence and performance: the role of self-other agreement on transformational leadership perceptions. Group and Organization Management, Vol. 24, pp. 367-390.

Swanson, R.A. (1995). Human resource development: Performance is the key. Human resource Development Quarterly. 6 (2), 207-213

Milliman, J., Czaplewski, A., \& Ferguson, J. (2003). Workplace spirituality and employee work attitudes. Journal of Organizational Change Management, 16(4), 426-447.

Luthans, F. (1998), Organizational Behavior, 5th ed., Irwin/McGraw-Hill, Boston, MA.

Swanson, R.A., \& Torraco, R.J. (1995). The history of training. In L. Kelly (Ed.), Technical and skills 
training handbook of the American Society for Training and Development. New York: McGrawHill.

Nohria, N., Lawrence, P., \& Wilson, E. (2001). Driven: How human nature shapes our choices. San Francisco: Jossey-Bass

Greenspan, S. I. (1989). Emotional intelligence. In K. Field, B. J. Cohler, \& G. Wool (Eds.), Learning and education: Psychoanalytic perspectives (pp. 209-243). Madison, CT: International Universities Press.

Eddy, E. R., Tannenbaum, S. I., Lorenzet, S. J., \& Smith-Jentsch, K. A. (2005). The influence of a continuous learning environment on peer mentoring behaviors. Journal of Managerial Issues, 383-395.

Harel, G.H., and Tzafrir, S.S.1999. "The Effect of Human Resource Management Practices on the Perceptions of Organizational and Market Performance of the Firm", Human Resource Management, 38(3), pp. 185-200

Crosby, P. B. (1996). The absolutes of leadership. Johannesburg ; San Diego: Pfeiffer \& Company. Lowder Page 26 Running head: A Meta-Analysis of Effective Leadership

Boyatzis, R., Goleman, D., \& Rhee, K. (2000). Clustering competence in emotional intelligence: Insights from the Emotional Competence Inventory. In R. Bar-On \& J. Parker (Eds.), The handbook of emotional intelligence: Theory, development,assessment and applications at home, school, and in the workplace (pp. 343-362).

House, R. J., \& Javidan, M. (2004). Overview of GLOBE. In R. J. House, P. J. Hanges, M. Javidan, P. W. Dorfman, \& V. Gupta (Eds.), Culture, leadership, and organizations: The GLOBE study of 62 societies (pp. 513-563). Thousand Oaks, CA: Sage Publications.

Mark A. Huselid, "The Impact of Human Resource Management Practices on Turnover, Productivity, and Corporate Financial Performance,” Academy of Management Journal, 1995, 38(3), 635-672.

Hair, J. F., B. Black, B. Babin, R. E. Anderson, and R. L. Tatham. Multivariate Data Analysis, 6th ed. Upper Saddle River, NJ: Prentice Hall, 2006

Ringle, Cristian Marc/Wende, Sven/Will, Alexander, SmartPLS, http:www.smartpls.de, SmartPLS, Hamburg, Germany, 2005

Van Deursen, A. J., Bolle, C. L., Hegner, S. M., \& Kommers, P. A. (2015). Modeling habitual and addictive smartphone behavior: The role of smartphone usage types, emotional intelligence, social stress, self-regulation, age, and gender. Computers in human behavior, 45, 411-420.

Zhang, L., Cao, T., \& Wang, Y. (2018). The mediation role of leadership styles in integrated project collaboration: An emotional intelligence perspective. International Journal of Project Management, 36(2), 317-330.

Froman, P. D. (2019). Emotional Intelligence as an Attribute of Fire Service Leadership.

Hallinger, P., \& Hosseingholizadeh, R. (2019). Exploring instructional leadership in Iran: A mixed methods study of high-and low-performing principals. Educational Management Administration \& Leadership, 1741143219836684.

Atan, J., \& Mahmood, N. (2019). The role of transformational leadership style in enhancing employees' competency for organization performance. Management Science Letters, 9(13), 2191-2200.

McDonough, J. D. (2017). Understanding Experiences Of Gratitude In Elementary Teachers: Implications For School Leaders.

Sullivan, P. S. (2017). The Relationship of Self-Awareness to Leadership Effectiveness for Experienced Leaders. 